\title{
O endomarketing como estratégia na gestão de pessoas: influências de clima e cultura nas organizações
}

The Endomarketing as a strategy in people management: climate influences and culture in organizations

Ana Aracelly Oliveira 1; Mayra de Castro Aquino 2; Wilian Toneli da Silva 3.

3 E-mail:

wtoneli@yahoo.com.br;

FUNORTE

\section{Resumo}

Esta pesquisa tem como proposta levantar os diversos significados do endomarketing, uma vez oriundo do marketing tradicional, o mesmo evoluiu para promover a comunicação interna entre administração, colaborador e seus elementos que compõem a gestão do endomarketing, objeto de estudo onde a análise aborda identificar os elementos comportamentais que integram o endomarketing na sua funcionalidade, em observação de sua percepção da influencia da gestão estratégia de endomarketing e mudanças perceptivas traduzidas no empenho da eficacia do endomarketing para com a valorização do capital humano revelada sob a ótica do colaborador sobre clima organizacional e cultura organizacional, motivação, satisfação e comprometimento, características estas ambientadas na organização em questão.

Palavras-chaves: $\quad$ Endomarketing; $\quad$ Clima Organizacional; Motivação; Satisfação.

\begin{abstract}
This research has proposed raising the various meanings of endomarketing a derived rather than traditional marketing, it has evolved to promote internal communication between management, employees and their component elements of internal marketing management, where the object of study analysis approaches to identify the behavioral elements that comprise the internal marketing in its functionality, in observation of their perception of the influence of internal marketing management strategy and perceptual changes reflected in the commitment of the effectiveness of internal marketing towards the enbancement of human capital revealed from the perspective of employees on organizational climate and culture organization, motivation, satisfaction and commitment, these characteristics acclimated in the organization in question.
\end{abstract}

Keywords: Endomarketing; Organizational climate; Motivation; Satisfaction. 


\section{Introdução}

Os processos de globalização do capital, das telecomunicações, da informação e do conhecimento, criam um cenário de competitividade cada vez mais acirrada. A utilização racional de todos os recursos se faz necessária para que as organizações tenham em mão uma ferramenta poderosa ao seu favor, a tomada de decisão. Porém mesmo com todo o conjunto de recursos, informação e conhecimento, nem sempre esse processo é tão fácil de alcançar.

Nesta época, onde as instituições evidenciam cada vez mais a realidade dos objetivos e metas almejados num mundo competitivo, os processos e ações de comunicação interna buscam propagar sua mensagem a seus colaboradores gerando um clima organizacional favorável ao entendimento da informação, transmitida de forma coletiva.

$\mathrm{Na}$ busca por vantagem competitiva, as organizações canalizam seus esforços na orientação estratégica de seus colaboradores, para com o cliente externo, ações de estímulos, bem como desenvolvimento através de comunicação orientada e treinamentos ofertados aos colaboradores, com a visão e missão da organização.

É fundamental que a gestão de pessoas, como canal direto de comunicação aos colaboradores, promova a ligação empresa/colaborador, diminuindo as distâncias entre as partes, tornando propícia a viabilidade de uma sincronia, fazendo a integração dos objetivos da organização como um todo.

Fomentar a capacitação desses colaboradores e mantê-los satisfeitos, é de extrema importância, se a organização deseja que seus clientes tenham a experiência de satisfação em adquirir produtos e/ou serviços. Através dos aspectos percebidos acerca do endomarketing, tem-se como objetivo geral apresentá-lo como meio viável de fomento ao crescimento organizacional, através da gestão eficaz dos colaboradores. Ressalta-se analisar os elementos comportamentais que integram o endomarketing, bem como as características do ambiente interno, aspectos de influência do endomarketing na construção da cultura organizacional e fatores motivacionais/comportamentais que servem de construção para a cultura e implementação do marketing interno. 


\section{Definição de endomarketing}

Segundo Bekin (1995), a definição de endomarketing aborda as ações de uma organização junto a seus colaboradores, onde os mesmo são considerados como clientes internos, acreditando estar bem sincronizada no ambiente interno, agregará, conseqüentemente, excelência em qualidade na prestação dos serviços para com o seu público externo.

Segundo Chiavenato (2009), a gestão de pessoas, mediante suas atribuições tem como responsabilidade a execução de alguns processos básicos da sua função, sendo eles: atrair; atribuir, desenvolver, recompensar, fidelizar e monitorar pessoas, são eles:

- Processo de atração: engloba o levantamento das necessidades de mão de obra, recrutamento, seleção e treinamento. É o processo que visa atrair indivíduos para a organização.

- Processo de atribuição: Corresponde em atribuir indivíduos a funções e cargos dentro da organização, orientando e acompanhando-os no processo, desenhando assim uma estrutura organizacional.

- Processo de desenvolvimento: Busca promover o desenvolvimento do colaborador através de treinamentos, capacitações e comunicação orientada aos objetivos da função a ser desempenhada, bem como objetivos gerais da empresa.

- Processo de recompensas: Visa recompensar os colaboradores conforme variantes préestabelecidas como metas e desempenho do indivíduo, com intenção de promover a motivação dos mesmos e o comprometimento para com a produtividade da organização.

- Processo de fidelização: Objeitva promover um ambiente favorável ao colaborador bem como a oferta de remuneração variável e recompensas, plano de benefícios e saúde, bem como uma comunicação acessível á administração da organização, gerando assim um clima organizacional que proporcione a satisfação do indivíduo.

- Processo de monitoramento: Corresponde ao acompanhamento das atividades dos colaboradores, controlando e verificando os resultados através de indicadores, sistemas específicos, auditorias, metas.

A esses processos administrados pela gestão de recursos humanos, remete uma comunicação objetiva e orientada aos objetivos da empresa junto aos colaboradores, com intuito dos mesmos se comprometerem com a organização, agregando assim qualidade e excelência, tanto no processo produtivo, quanto no produto final. 
As organizações buscando aprimorar cada vez mais, a consideração de seus colaboradores como clientes internos, utiliza-se da gestão estratégica de pessoas, para descobrir e reter talentos, motivando-os e direcionando-os para os objetivos que a organização deseja alcançar.

Partindo do pressuposto de que o cliente interno, conhecedor do produto e ou serviço ofertado, torna-se importante se fazer consultar junto aos colaboradores, através de opiniões sobre os produtos por eles produzidos, fazendo-o acreditar e aceitar, o que, por conseguinte, refletirá em resultados da satisfação e aceitação do cliente, sendo o colaborador considerado o primeiro cliente da organização.

Diante da acirrada competição por mercado consumidor, as empresas se lançam em práticas competitivas, notadamente, o uso estratégico do endomarketing que implica na necessidade da organização em se manter coesa, com colaboradores satisfeitos e sincronizados para com os objetivos da empresa, refletindo assim para o mercado consumidor uma imagem empresarial forte, estável, de qualidade e excelência em atendimento.

Bekin (2004) defende que "ações de marketing voltadas para o público interno da empresa, com o fim de promover entre seus funcionários e departamentos valores destinados a servir o cliente".

Segundo Kotler (2000), o marketing tem um envolvimento social, levando o consumidor a interessar-se pelos produtos de forma criativa e renovada, oferecendo um serviço de qualidade, quando dos trabalhos prestados.

O endomarketing utiliza-se de um conjunto de ações de marketing orientado para os colaboradores, como também para fornecedores acionistas, ou seja, para seu público interno. Voltado para o relacionamento interno, o endomarketing aborda aspectos da emoção, valores, crenças, participação e motivação junto a seus colaboradores.

O endomarketing tem sua ramificação do marketing tradicional, conforme Bekin (1990), seu criador, que explicita o termo em seu livro "Fundamentos do Endomarketing". A palavra "endo", do radical grego, que dizer "movimento para dentro", onde se traduz no endomarketing e sua funcionalidade interna na organização, tendo como público alvo os colaboradores e demais agentes internos da organização. 


\section{Fundamentos do endomarketing}

Bekin (2004) ainda aborda os seguintes fundamentos do Endomarketing:

- Definição: A utilização do marketing para com o público interno no ambiente organizacional.

- Conceito: Metodologia de marketing, com meta na inter-relação de informações entre organização e colaboradores, com foco no cliente externo.

- Objetivo: Realizar uma absorção e sincronia da comunicação e valores repassados aos colaboradores, criando e fortalecendo uma relação entre organização e seus indivíduos.

- Função: Implicar estrategicamente o conceito de cliente interno junto aos processos produtivos, a fim de criar e propagar valores, propiciando harmonia, melhorias e qualidade na produtividade.

Conforme Kotler (2003), o endomarketing utiliza-se das ferramentas do marketing para vender a seus colaboradores os ideais da empresa, bem como, sua missão e objetivos, notadamente apresentado ao colaborador, campanhas internas, a fim de que o mesmo crie uma sincronia com a empresa.

Segundo Bekin (1995), as práticas do endomarketing estão voltadas diretamente para o público interno, fazendo com que haja um reflexo positivo da promoção dos valores da organização para com o cliente final.

Vender o produto para seu cliente interno é tão importante quanto vender para o cliente externo, a prática do endomarketing, derivada do marketing tradicional possibilita às organizações estreitarem seus relacionamentos junto aos seus colaboradores.

Segundo Kotler e Keler (2006), uma organização pode usufruir de um excelente serviço de marketing, contudo, não significa acerto nessa área, para se obter sucesso é importante a percepção dos clientes por parte dos demais setores.

Bekin (1995, 1995, p. 2) afirma que:

O endomarketing consiste em ações de marketing voltadas para o público interno da empresa, com o fim de promover entre seus funcionários e departamentos, valores destinados a servir o cliente. Esta noção de cliente, por sua vez, transfere-se para o tratamento 
dado aos funcionários comprometidos de modo integral com os objetivos da empresa.

O envolvimento dos colaboradores junto à organização favorece uma sincronia dos objetivos da mesma, tornando propício a diminuição de obstáculos a mudanças na empresa.

A gestão estratégica do endomarketing viabiliza junto aos colaboradores a percepção de valorização, bem como a visão de sua relevante importância para a organização, onde, notadamente, constrói-se um ambiente favorável e harmonioso, visando proporcionar qualidade e excelência nos serviços prestados.

Tanto o cliente interno, quanto o cliente externo, exprimem sua confiança na organização devido ao endomarketing.

A utilização do endomarketing como ferramenta estratégica visa obter junto aos colaboradores, que os mesmos tenham uma plena noção de que os serviços prestados tenham a finalidade de satisfazer o cliente externo, e esse comprometimento faz com que os colaboradores possam tirar dúvidas, falar das especificações e orientações sobre produtos e serviços oferecidos.

Conforme Chiavenato (2005), com objetivo de fomentar a motivação dos colaboradores, observa-se que não somente as necessidades básicas devem ser supridas, mas também devese verificar os fatores motivacionais, fatores estes, abordados na teoria de Maslow, com referência para aspectos da realização e reconhecimento.

\section{O endomarketing e sua importância na organização}

Segundo Brum (2005), para as organizações existe uma necessidade constante de mudança em suas marcas, produtos e serviços, mudança esta, que estabelece diferenciação e consequentemente o torna mais competitivo no mercado, consoantemente é necessário tal abrangência de esforços na valorização dos colaboradores, com objetivo implícito de tornálos mais motivados e consequentemente satisfeitos.

As organizações tendo vistas de que o mercado consumidor é complexo e competitivo, compreende a necessidade de tornar os colaboradores uma extensão da empresa onde atuam, 
capacitando, orientando e motivando-os com o objetivo de criar um ambiente favoravél e confiante. Notadamente as organizações, para tal feito buscam recorrer ao seu recurso intangível, ou seja, o capital humano, como diferencial na competição por excelência em qualidade o que consequentemente abre espaço na sua área de atuação.

Lacombe (2005), defende que os colaboradores são agentes de transformação das organizações, onde agregados a eles estão condicionados aspectos como motivação e por conseguinte a satisfação; que conduz a maximização da produção, onde por sua vez, os colaboradores tendo suas necessidades satisfeitas executam com qualidade o atendimento e demais processos produtivos, fazendo com que a organização se aproxime das metas e objetivos desejados.

Para Brum (2007), as organizações que fazem uso da prática do endomarketing, evidenciam, no decorrer do processo, um total clima de entusiasmo, consequência esta, observada nas transformações positivas da sua prática na organização.

Notadamente Brambilla (2005), afirma que a natureza do endomarketing, se objetiva primeiramente em fidelizar o seu primeiro cliente, ou seja, o colaborador, trazendo para junto de si orientando-o, ressaltando os objetivos e missão da organização.

Com a finalidade de se buscar a excelência nos serviços prestados, as organizações buscam obter a satisfação de seus clientes, contudo, a mesma volta-se para seu interior e utiliza-se do endomarketing na compreensão de que o capital humano é mola propulsora pois satisfazendo seu público interno. consequentemente estará cada vez mais promovendo a satisfação do seu público externo.

Agindo incisivamente nos colaboradores, o endomarketing tem sua funcionalidade, atuando sobre evoluções positivas e até mesmo crises em que a organização esteja vivenciando, tornando assim os colaboradores cientes da realidade da empresa e participantes ativos como parceiros para resoluções de conflitos, dúvidas e demais interações entre empresa e cliente externo.

O endomarketing trata diretamente nos funcionários quando, informa-os sobre determinada crise e os orienta sobre como devem abordar o assunto junto ao público externo, os tornando capazes de auxiliar a empresa no enfrentamento e superação do problema. 
Segundo Brum (1998), é ressaltado que determinados fatores devem ser levados em consideração, pela sua importância para o sucesso do programa de endomarketing, como os aspectos da cultura dos indivíduos que é notadamente relevante para o alinhamento dos valores entre colaborador e organização, desenvolvendo e proporcionando assim uma cultura organizacional positiva.

As empresas têm investido muito em adotar diferenciais competitivos, para oferecer seus produtos e serviços, com isso, os investimentos em recursos humanos da empresa resumemse em uma ferramenta de gestão estratégica, onde se investe em capacitação, condicionando o colaborador a uma evolução profissional, resultando em melhorias que se refletem no trato interno, atendimento e atenção para com o cliente.

Conforme Corrado (1994), percebe-se que a utilização do endomarketing acarreta numa produtividade maior, bem como, observa-se um maior comprometimento por parte dos colaboradores, uma vez que, a organização oferta-lhes condições favoráveis, que geram valor na execução dos processos produtivos.

Ainda conforme o autor supracitado (1994), os clientes internos na figura dos colaboradores, sofrem diretamente a influência da cultura da organização, absorvendo seus valores, contudo, a percepção das informações que os indivíduos necessitam, divide-se em dois tipos:

1) Precisam estar cientes da organização como um todo, seus valores, conceitos, visão, missão e objetivos, bem como sua participação na organização como agente transformador; 2) Precisam estar cientes dos benefícios, treinamentos e capacitações, remuneração, avaliação de produtividade e valorização hierárquica.

A compreensão da organização, bem como seu aspecto gerencial, devem ser voltados para um objetivo bem definido, onde os colaboradores serão os agentes ativos na construção e fomentadores dos objetivos da empresa, notadamente, orientados pelo setor de Recursos Humanos.

Para Kotler (2000), o endomarketing emoldura-se de uma ferramenta de parceria com o setor de Recursos Humanos, que exerce papel de doutrinação e determinação dos colaboradores, objetivando uma excelência no atendimento do serviço prestado.

Conforme Bekin (1995), o endomarketing é uma ferramenta estratégica na gestão de pessoas, com foco de ação no cliente interno da organização. 
A pluralidade do ideal do endomarketing exerce sua influência na transformação do clima organizacional, onde o setor de Recursos Humanos pulveriza através das mídias internas, informações fazendo com que os colaboradores tenham sua real percepção de transformador do seu meio, corroborando com a ideia de que o mesmo é um agente ativo, o colaborador se vê tanto defensor quanto responsável para o êxito dos objetivos, uma vez que, é sabido por ele que o bom desempenho de seu papel resultará num alcance de um objetivo comum.

É de responsabilidade da administração, à frente da gestão do capital humano da empresa, o setor de recursos humanos se faz detentor de ferramentas que mensuram analisar e avaliar o padrão de motivação e satisfação dos colaboradores no ambiente organizacional, identificados os fatores da satisfação e motivação, sejam eles traduzidos nos quesitos benefícios, relacionamento interpessoal, salário, dentre outros, para assim obter uma melhor objetividade na gestão de pessoas.

Para Ponchirolli, (2000), o que forma a parte mais importante do valor de uma empresa são as estratégias desenvolvidas para recruta, desenvolvimento e recompensa dos colaboradores.

Segundo Nassar (2002):

[...] cabe à gestão de comunicação e de recursos humanos a tarefa conjunta de habilitar todas as pessoas da organização para as questões ligadas ao simbólico organizacional. O que significa, principalmente, melhorar a qualidade dos relacionamentos e da comunicação da empresa. Isto porque os processos mais estratégicos relacionados à construção ou demolição da imagem empresarial passam pela forma como as pessoas da organização (incluindo os seus gestores) estão trabalhando e se relacionando com os seus públicos estratégicos. (Nassar, 2002, p, 1).

A organização coesa adquire uma identidade onde a mesma é compartilhada por todos, contudo, deve-se sempre mensurar os fatores que determinam que essa identidade seja positiva para benefício da organização e seus elementos participantes, ou seja, a gestão estratégica de pessoas deve ser voltada também para determinar a medida de seus objetivos, se estão trabalhando de forma continuada. 
Segundo Moutella (2005), a organização deve ter como objetivo a construção mais interativa do relacionamento empresa/colaborador, buscando assim um maior comprometimento e forma de trabalho em equipe que com esse trabalho em conjunto, a organização transmite a imagem de confiança, de organização e excelência em qualidade no atendimento, bem como uma visível relação positiva entre empresa e empregado.

Bekin (1995), ressalta aspectos do endomarketing junto aos colaboradores:

O grande desafio do Endomarketing é proporcionar aos empregados uma condição de aplicação de valores como: transparência, empatia, afetividade, comprometimento e cooperação, transformando esses valores em crescimento e desenvolvimento dos empregados, e consequentemente, em ganhos de produtividade. (Bekin, 1995, pág.17).

Notadamente, a organização vendo necessária a mudança para ganhar espaço no mercado altamente competitivo, volta-se estrategicamente para seu público interno, contudo, a administração deve promover mudanças significativas, que promovam confiança e responsabilidade, um modelo a ser seguido pelos colaboradores e que os mesmos venham participar e perceber o que a organização tem a ofertar, para fazer acontecer quando assim instituir o endomarketing no ambiente organizacional.

Lawler III (1998), defende que o colaborador deve tomar para si a postura de agente transformador, assumindo seu comprometimento pela sua atuação profissional e consequentemente seus impactos na figura da empresa. Tal postura o condiciona a posicionar-se de modo consciente como elemento modificador que agregará qualidade nos serviços e produtos oferecidos, fazendo com que a organização se torne mais competitiva no mercado.

[...] o segredo para se conseguir o engajamento dos funcionários aos objetivos da empresa, é convencendo-os de que sua participação e sua vontade [...] são fundamentais para sobrevivência da companhia e, portanto, para a manutenção dos empregados. É importante entender que, em uma economia globalizada, a segurança no emprego vem do fato de a empresa ser competitiva. (Lawler III, 1998, p. 13). 


\section{Definição de clima organizacional e fatores motivacionais}

Segundo Luz (2003), o clima organizacional compreende aspectos motivacionais, cultura da organização, satisfação e a objetivação da organização percebida pelos indivíduos, bem como acerca da junção desses aspectos que se faz identificar meios estratégicos para a realização de decisões, conhecendo assim seus fatores determinantes e reflexos.

Para Bekin (2004), o processo de estabelecer uma inter-relação com o colaborador volta-se para fomentar a condição de motivação percebida pelo indivíduo, condição esta, que deve ser constante.

O colaborador motivado torna-se incentivador de si próprio, quando os fatores que o levam a estar motivado conspiram diretamente na obtenção de suas metas e objetivos, trazendo consigo a satisfação de se conseguir o que se deseja.

Segundo Brum (1998), alguns fatores motivacionais trabalhados pela organização e percebidos pelos colaboradores são:

- Reconhecimento;

- Participação nas decisões;

- Liderança participativa;

- Promoções;

- Remuneração e benefícios;

- Liberdade criativa.

Conforme Maslow (1954) apud Marras (2007), a motivação é o fator mais importante no alcance da satisfação, dado à necessidade na busca do objetivo desejado, a motivação se torna crescente e, uma vez satisfeito, o indivíduo fica condicionado a uma busca cada vez mais constante no alcance do seu objetivo, criando assim um ciclo representado pela teoria de Maslow.

FIGURA 1 - Pirâmide das necessidades humanas de Maslow.

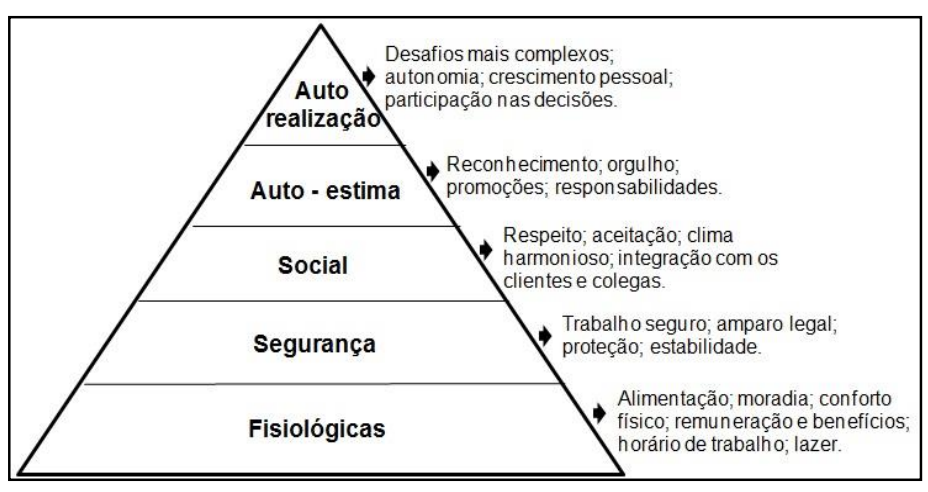


Fonte: Adaptado de CHIAVENATO, I. A dinâmica do sucesso das organizações. São Paulo: Thomson, 2004.

Para Maximiano (2007), as abordagens que fomentam a motivação dos colaboradores englobam fatores de compreensão de incentivos que se traduzem numa melhora no desempenho dos colaboradores quando assim satisfeitos. A organização utiliza-se desde elogios, premiações, benefícios, bônus. Tais praticas motivacionais resultam na qualidade do produto ou serviço para com o cliente final.

A persistência dos estímulos que levam o colaborador a esta motivado devem ser contínuos e sempre verificados conforme seu atingimento para com o colaborador, mensurando assim seu grau de comprometimento e desempenho. Notadamente, é importante que o exercício do endomarkting seja sempre constante para implicar no cotidiano do meio organizacional.

Segundo Cerqueira (1994), o endomarketing modificando o clima organizacional, vem contribuir para com a cultura da empresa, contribuindo qualitativamente para a percepção e ideal de realização e comprometimento dos colaboradores bem como a satisfação obtida pela resolução de problemas e seus desafios.

Para Bekin (2004, p. 99), a chave para se obter o sucesso é através da valorização do capital humano, onde essa expectativa se dá através de ações estratégicas do endomarketing.

\section{METODOLOGIA}

A metodologia utilizada no presente trabalho tem o seu embasamento no processo técnico de criação à pesquisa bibliográfica.

Segundo Gil (2002) a referente pesquisa ressalta que o pesquisador faça uso de investigação e construa sua pesquisa com base em material já elaborado, possibiltando ao pesquisador maior amplitude de conhecimento diante de sua investigação. Fora pesquisado o objeto proposto em livros, artigos científicos, monografias, revistas, mídia digital.

Diante da proposta do estudo em questão e seu desenvolvimento, para com a realização da pesquisa, a mesma caracteriza-se como descritiva, explicativa e de revisão bibliográfica, onde fora abordado o tema através da revisão de literatura sobre a linha de pesquisa "Endomarketing”, realizada através de consultas em livros didáticos, artigos, dissertações, projetos, internet. 
Conforme Marconi e Lakatos (1992),

A pesquisa de referencia bibliográfica engloba a apuração de toda a bibliografia publicada no meio encontrada em revistas, internet, artigos, tal pesquisa resulta com que o individuo venha abranger sua linha de pesquisa com todo o material exposto referente ao objeto de estudo, contribuindo assim na sua análise.

\section{Primeira etapa - Fontes}

Apresenta-se as fontes que foram exploradas o assunto em questão na busca de respostas:

a) Livros com referência ao assunto proposto e demais assuntos afins, que contribuem para o tema foram consultados, os mesmo se encontram na língua nativa do país, o idioma português, sendo que alguns se encontram disponíveis na forma digital, publicados entre os anos de 1995 a 2008.

b) Foram consultados artigos nacionais oriundos da base de informações gratuitas, da base de dados do portal contábil, bem como IBGE e site do conselho regional de administração no período apreciado entre 2000 a 2014, com referência ao endomarketing e sua funcionalidade.

Dos meios explorados, as fontes escolhidas foram as que se tratavam do assunto proposto, as demais fontes de perfil não adequado foram excluídas.

\section{Coleta de dados}

Da coleta dos dados explorados nas fontes selecionadas tiverem o seguinte procedimento:

a) Leitura e interpretação de obras relacionadas ao assunto.

b) Análise de assuntos selecionados, mediante a leitura do conjunto em questão.

c) Extração e registro das informações coletadas, bem com da sua interpretação e seus autores e especificidades em questão. 


\section{Análise e interpretação dos Resultados}

Objetivando a elucidação dos problemas, esta etapa se dá pela análise das informações, com base em uma leitura analítica e ordenada.

\section{Discussão do dados}

A discussão das informações mediante sua análise observando-se o objeto proposto.

\section{Cuidados éticos}

Com base no cumprimento da norma regulamentadora 6023, houve o critério de se respeitar e citar os autores envolvidos, uma vez que, a proposta da pesquisa é de finalidade cientifica.

\section{RESULTADOS E DISCUSSÃO}

A discussão abordada aponta que a inserção do endomarketing na organização é sempre positiva, uma vez que, diante de sua utilização evidencia-se a eliminação das distâncias entre colaborador e administração e proporcionalmente, diminue a resistência às mudanças, onde ao instaurar o endomarketing se verifica o ambiente interno e o molda às pesrpectivas futuras da empresa, contudo, é feito o levantamento de fatores que levam a proporcionar um clima organizacional favorável, como promover a motivação e a satisfação do colaborador.

De acordo com Bekin (2004), a administração da organização deve voltar suas atenções para a valorização do colaborador bem como sua importância na empresa, construindo assim, percepções como reconhecimento, segurança, valorização e confiança.

O objetivo é que o colaborador tenha noção da importância da empresa onde o mesmo exerce seu trabalho. Ciente de sua importância, o colaborador desenvolverá a confiança na organização e no seu trabalho, trazendo consigo um clima organizacional favorável ao desenvolvimento de suas atribuições e uma visão positivista da empresa interna e externamente.

Para Chiavenato (2002), pode-se imaginar o quanto o endomarketing será importante para o crescimento dos negócios nesse cenário e o quanto representará para as empresas que 
souberem como estruturar seus planos de abordagem aos empregados, visando a máxima qualidade do produto ou serviço que oferecem aos seus clientes.

Segundo Bekin (2004, p. 99) "o endomarketing em concomitância com a comunicação interna gera envolvimento, que gera comprometimento, que gera motivação, que, por sua vez, é mantida pelo processo de comunicação" corroborando para a valorização do capital humano, favorecendo assim o ambiente interno.

A comunicação interna instrui, educa e é o canal potencializador do colaborador, orientandoo e verificando junto ao mesmo o seu grau de comprometimento e satisfação.

Brum (1998), defende que para a inserção do endomarketing dentro de uma organização, as ferramentas utilizadas na implantação de um plano de marketing também podem ser utilizadas no plano de endomarketing, contudo, para um alcance mais objetivista são utilizados ferramentas compatíveis com os parâmetros do projeto de endomarketing a ser colocado em prática.

Ainda conforme o autor supracitado (1998), o mesmo descreve algumas ferramentas de comunicação, utilizadas para inserir e ou melhorar o endomarketing:

- Pesquisa de satisfação;

- Material informativo sobre o programa;

- Jornal de circulação interna;

- Cartazes com temas motivacionais e informativo;

- Painéis;

- Folders;

- Palestras internas;

- Intranet.

O endomarketing atuante na comunicação e promoção da organização se torna mais evidenciada no dia a dia dos colaboradores, onde os mesmos, estando satisfeitos, desenvolvem melhor a inter-relação entre os demais membros bem como o seu comprometimento e anseio em promover sempre o melhor de si, tornando a imagem da organização forte, agregando assim qualidade e excelência ao produto e ou serviço ofertado. 


\section{CONSIDERAÇÕES FINAIS}

As organizações, na busca de um diferencial competitivo fazem uso da estratégia de endomarketing, criando assim uma imagem forte e consolidada, bem como referência em qualidade e atendimento, onde notadamente se mostra eficaz na interação empresa/colaborador.

Este fator promove o comprometimento do cliente interno para com os objetivos e anseios da organização diminuindo distâncias e resistências a mudanças, construindo assim uma imagem forte, onde os objetivos da organização são compartilhados por todos.

O desenvolvimento do presente trabalho objetivou expor de forma clara e objetiva o endomarketing, trazendo à luz do conhecimento, seus aspectos e características junto a sua funcionalidade perante a organização.

Ao explorar o tema proposto, fica notório os benefícios e importância do endomarketing nas organizações, uma vez que, esta ferramenta tem finalidade de estreitamento entre organização e colaborador.

O presente estudo aponta também que colaboradores motivados são mais propícios a serem mais produtivos, os mesmos estando satisfeitos desenvolvem valores e demonstram comprometimento junto á organização, consolidando os objetivos e desejos de ambos.

Concomitantemente, observou-se que os aspectos que determinam a criação do endomarketing na organização favorece a criação de um clima organizacional positivo que, por conseguinte, irá gerar uma cultura organizacional favorável à disseminação dos valores e crenças da organização, criando assim uma personalidade onde organização e colaborador vislumbram objetivos comuns.

Observou-se também, que diante da consolidação das relações internas, junto ao comprometimento dos colaboradores e favorecimento à criação de um clima e cultura favorável, a organização consolida-se como uma empresa coesa, de marca forte e imagem empresarial positiva. Notoriamente, ressalta-se que, preparar o ambiente para tal projeto, deve ser muito bem analisado e após tê-lo feito, deve-se fazer com que, constantemente, seja reavaliado e modificado, tanto para o mercado consumidor, quanto para os objetivos da organização, visto que, os objetivos da empresa estão voltados sempre para o mercado. 


\section{REFERÊNCIAS BIBLIOGRÁFICAS}

BEKIN, Saul Faingaus. Endomarketing: como praticá-lo com sucesso. São Paulo: Prentice Hall, 2004.

Saul Faingaus. Conversando sobre endomarketing. São Paulo: Makrons Books, 1995.

BUENO, Eduardo. Gestão do conhecimento e Capital Intelectual. Disponível em: http://www.portalcontábil.com.br. Acessado em 29 maio de 2014.

BRAMBILLA, F. R. Abordagem conceitual de marketing interno. REAd, 43. Ed., Vol. 11, $\mathrm{N}^{\mathrm{o}}$ 1, jan-fev 2005.

BRUM, A. M. Endomarketing de A a Z. Porto Alegre: Dora Luzzatto, 2007. 254 p.

A. M. Endomarketing como Estratégia de Gestão: Encante seu Cliente Interno. Porto Alegre: L\&PM, 2005.

A. M. Endomarketing como Estratégia de Gestão: Encante seu Cliente Interno. Porto Alegre: L\&PM, 1998.

CERQUEIRA, Wilson. Endomarketing, educação e Cultura para a qualidade. Rio de Janeiro: Qualitymark, 1994.

CHIAVENATO, Idalberto. Gestão de pessoas: o novo papel dos recursos humanos nas organizações. Rio de Janeiro. Ed. Campus, 2009.

Idalberto. Comportamento organizacional: a dinâmica do sucesso das organizações. $2^{\circ}$ ed. Rio de Janeiro. Ed. Elsevier, 2005.

Idalberto. Construção de Talentos. As Novas Ferramentas da Gestão de Pessoas. Rio de Janeiro: Campus, 2002.

1999. 194p.

Idalberto. Administração de recursos humanos. 4.ed. SÃO PAULO: Atlas,

CORRADO. Frank M. A força da Comunicação. São Paulo: Makron Brooks, 1994. 245 p.

GIL, Antonio Carlos. Como elaborar projetos de pesquisa. 4. ed. São Paulo: Atlas, 2008.

$\overrightarrow{2002}$ Antonio Carlos. Como elaborar projetos de pesquisa. 4. Ed. São Paulo: Atlas.

Antonio Carlos. Métodos e Técnicas de Pesquisa Social. São Paulo: Atlas, 1995.

KOTLER, P. Administração de Marketing. 10. ed. São Paulo: Atlas, 2000.

Philip. Marketing de A a Z. 9.ed. RIO DE JANEIRO: Campus, 2003. 
Philip; KELLER, Kevin Lane. Administração de Marketing. Trad. Mônica Rosenberg, Brasil Ramos Fernandes, Cláudia Freire. 12. ed. São Paulo: Prentice Hall, 2006.

OLIVEIRA, Silvio Luiz de. Tratado de Metodologia Cientifica. Ed. Pioneira. $2^{\text {a }}$ ed, 1999.

LACOMBE, Francisco José Masset. Recursos humanos: princípios e tendências. São Paulo: Saraiva 2005.

LAKATOS, Eva Maria; MARCONI, Maria de Andrade. Metodologia científica: ciência e conhecimento científico, métodos científicos, teoria, hipóteses e variáveis. 2. ed. São Paulo: Atlas, 1992. 249 p.

LAWLER III, Edward. Estratégia versus funcionários. Entrevista cedida a HSM Management. no 10, p. 12-15, set / out. de 1998.

LUZ, Ricardo. Clima organizacional. 1 ed. Rio de Janeiro: Qualitymark, 2003. 52 p.

Nakalski, J; Santos, D. O Endomarketing em uma Empresa de Comunicação: Caso RBS TV Chapecó. XXXII. Encontro da Enampad. Rio de Janeiro, 2008.

MASLOW, Abraham H. Motivation and personality. New york, Haper \& Row Pubisher, 1954. Apud MARRAS, Jean Pierre. Administração de recursos humanos: do operacional ao estratégico. $3^{\circ}$ ed. Rio de Janeiro: Futura, 2000. 332 p.

MAXIMIANO, A. C. A introdução à administração. 7. ed. São Paulo: Atlas, 2007.

MOUTELLA, Cristina. Foco no cliente: estratégia de fidelização. Disponível no site: http://www.iis.com.br/ moutella. Acessado em 22 de setembro de 2014.

NAKALSKI, J; Santos, D. O Endomarketing em uma Empresa de Comunicação: Caso RBS TV Chapecó. XXXII. Encontro da Enampad. Rio de Janeiro, 2008.

PONCHIROLLI, Osmar. O Capital Humano como Elemento Estratégico na Economia da Sociedade do Conhecimento sob a Perspectiva da Teoria do Agir Comunicativo. Florianópolis: UFSC, 2000.

SPILLER, E. S. et al. Gestão de Serviços e Marketing Interno. 2. ed. Rio de Janeiro: FGV, 2006.

TOGATLIAN, M. A. Metodologia de pesquisa. 2010. Disponível em: http://www.togatlian.pro.br/docs/pos/unesa/instrumentos.pdf. Acessado em: 30 de maio de 2014. 